\title{
Mitochondrial dysfunction attenuates rapid regeneration in livers with toxin-induced fibrosis
}

\author{
Zheyong $\mathrm{Li}^{1,2 \#}$, Yuelong Liang ${ }^{1,2 \#}$, Hanning Ying ${ }^{1,2}$, Mingyu Chen ${ }^{1,2}$, Xiaoyan $\mathrm{He}^{2,3}$, Yifan Wang ${ }^{1,2}$, \\ Yifan Tong ${ }^{1,2}$, Xiujun Cai ${ }^{1,2}$ \\ ${ }^{1}$ Department of General Surgery, Sir Run Run Shaw Hospital, School of Medicine, Zhejiang University, Hangzhou, China; ${ }^{2}$ Zhejiang Provincial Key \\ Laboratory of Laparoscopic Technology, Sir Run Run Shaw Hospital, School of Medicine, Zhejiang University, Hangzhou, China; ${ }^{3}$ Department of \\ Biological Treatment Research Center, Sir Run Run Shaw Hospital, School of Medicine, Zhejiang University, Hangzhou, China \\ Contributions: (I) Conception and design: X Cai, Y Tong; (II) Administrative support: X Cai, Y Tong; (III) Provision of study materials or patients: X \\ Cai, YF Tong; (IV) Collection and assembly of data: Z Li, Y Liang, Y Tong, H Ying, M Chen, X He, Y Wang; (V) Data analysis and interpretation: Z \\ Li, Y Liang, Y Tong, H Ying, M Chen, X He, Y Wang; (VI) Manuscript writing: All authors; (VII) Final approval of manuscript: All authors. \\ \#These authors contributed equally to this work. \\ Correspondence to: Xiujun Cai, MD, FACS, FRCS; Yifan Tong, PhD. Department of General Surgery, Sir Run Run Shaw Hospital, School of \\ Medicine, Zhejiang University, Hangzhou 310000, China. Email: srrsh_cxj@zju.edu.cn; tongyf@zju.edu.cn.
}

Background: The mechanism of associating liver partition and portal vein ligation for staged hepatectomy (ALPPS)-induced rapid liver regeneration remains poorly documented, especially in patients with fibrosis. Therefore, this study aims to investigate the underlying mechanism of ALPPS-induced accelerated regeneration in toxin-induced fibrosis models.

Methods: The ALPPS-induced regeneration model was established in livers with thioacetamide (TAA)induced fibrosis to determine the regenerative pathways involved in rapid regeneration. Confirmatory experiments were performed in transforming growth factor beta 1 (TGF $\beta 1$ )-treated AML12 cells and mice with carbon tetrachloride $\left(\mathrm{CCl}_{4}\right)$-induced fibrosis. Finally, mitochondrial dysfunction was validated in fibrotic/non-fibrotic patients.

Results: In TAA-induced fibrotic mice, ALPPS-induced regeneration was significantly inferior to that of the control group $(\mathrm{P}=0.027$ at day 2 and $\mathrm{P}<0.001$ at day 7$)$. Furthermore, mitochondria-associated genes were significantly downregulated in TAA-challenged mice. Accordingly, the reduced production of ATP and elevated levels of malondialdehyde indicated disturbances in intracellular energy metabolism during the ALPPS-induced regenerative process after TAA treatment. Further investigations were performed in TGF$\beta 1$-treated AML12 cells and $\mathrm{CCl}_{4}$-treated mice, which indicated that mitochondrial dysfunction attenuated the capacity for rapid regeneration after ALPPS.

Conclusions: In summary, this study revealed that mitochondrial dysfunction led to inferior regeneration in livers with toxin-induced fibrosis and identified new therapeutic targets to improve the feasibility and safety of the ALPPS procedure. Further studies in human patients are required in the future.

Keywords: Associating liver partition and portal vein ligation for staged hepatectomy (ALPPS); fibrosis; regeneration; mitochondrial dysfunction

Submitted Jun 11, 2020. Accepted for publication Dec 24, 2020.

doi: $10.21037 /$ atm-20-4639

View this article at: http://dx.doi.org/10.21037/atm-20-4639 


\section{Introduction}

Associating liver partition and portal vein ligation for staged hepatectomy (ALPPS) has attracted interest due to accelerated hypertrophy of future liver remnants (FLRs) by ligating the branch of the portal vein combined with transecting the parenchyma to improve surgical resection rates $(1,2)$. Despite the significant improvements in morbidity and mortality, the feasibility and safety of ALPPS in patients with fibrosis remain controversial $(3,4)$. Many ALPPS recipients suffer from chronic hepatitis virus infections, alcoholism, or nonalcoholic liver diseases, which may progress to liver fibrosis and cirrhosis, post-hepatectomy liver failure caused by an insufficient proliferation of FLRs can give rise to life-threatening complications associated with the ALPPS procedure. As suggested by studies showing that regenerative capacity is impaired in livers with fibrosis, FLR hypertrophy after ALPPS is negatively correlated with the degree of fibrosis $(5,6)$.

The Indian Hedgehog (IHH) pathway, mitochondrial function, and the transcriptional landscape during ALPPSinduced regeneration have been previously illustrated (7-10). However, attenuation of regeneration in livers with fibrosis during ALPPS has not been well documented. The development and progression of hepatic fibrosis negatively regulate hepatocyte self-renewal by remodeling the microenvironment, intercellular interactions, changes in lipid and energy metabolism, and activation of targeted pathways, which comprehensively impairs rapid regeneration in livers with fibrosis (11-13). Mitochondrial dysfunction has emerged as an important factor in the regulation of liver physiology, including liver regeneration. Growing evidence has shown that mitochondrial dysfunction, namely mitochondrial morphological changes, mitochondrial membrane potential, structural damage, mitochondrial DNA damage, reactive oxidative species production, will attenuate regeneration livers with fibrosis (14). Furthermore, a previous study demonstrated that impaired mitochondrial function and biogenesis, along with the rapid energy-demanding cell proliferation, could cause hepatocyte dysfunction after ALPPS (9).

Therefore, this study aims to explore the key mechanism by which ALPPS-induced liver regeneration is attenuated in the context of fibrosis. Mitochondrial dysfunction during ALPPS-induced regeneration in livers with fibrosis was preliminary documented in this study, which may provide insights into new therapeutics and improve the surgical feasibility and safety of ALPPS in patients with liver fibrosis.

We present the following article following the ARRIVE reporting checklist (available at http://dx.doi.org/10.21037/ atm-20-4639).

\section{Methods}

\section{Ethics and animals}

Experiments were performed under a project license (No. 11836) granted by the Animal Ethics Committee of Sir Run Run Shaw Hospital, Zhejiang University, China, in compliance with the Animal Ethics Committee of Sir Run Run Shaw Hospital's guidelines for the care and use of animals. The study was conducted following the Declaration of Helsinki (as revised in 2013). The Human Ethics Committee approved the study of Sir Run Run Shaw Hospital, Zhejiang University, China (No. 20180226-25), and informed consent was obtained from all individual participants.

Male C57BL/6J mice aged 8-9 weeks $(n=72)$ were obtained from the experimental animal center of Zhejiang Province, China, and were housed in a restricted-access room with a controlled temperature $\left(23^{\circ} \mathrm{C}\right)$ and a 12 -hour light-dark cycle. Mice had free access to food and water before and after treatments. For the thioacetamide (TAA)induced model, $2 \mathrm{~mL} / \mathrm{kg}$ TAA (concentration $=0.05 \mathrm{~g} / \mathrm{mL}$ ) was administered twice per week by intraperitoneal injection for 12 consecutive weeks. For the carbon tetrachloride $\left(\mathrm{CCl}_{4}\right)$-induced model, $20 \% \mathrm{CCl}_{4}\left(\mathrm{CCl}_{4}\right.$ :oil $=1: 4)$ at a dose of $5 \mathrm{mg} / \mathrm{kg}$ was administered twice per week by intraperitoneal injection for 6 consecutive weeks. Each group contained 5 mice.

\section{ALPPS procedure}

Two days after the last drug treatment, the ALPPS procedure was performed in mice that had been fasted for 8 hours. The operation details were similar to those described in a previous study (6). The mice were placed under general anesthesia using an automatic delivery system (1\% isoflurane with a rate of $400 \mathrm{~mL} / \mathrm{min}$ in the induction phase and $250 \mathrm{~mL} / \mathrm{min}$ in the maintenance phase), and a surgical microscope was used during the entire surgical procedure (Figure S1A). After the cholecystectomy, the portal vein branches supplying the left lateral, left middle, right, and caudate lobes were microscopically ligated with a 9-0 silk suture. The artery and biliary duct branches were maintained. Next, parenchymal transection was performed through the middle lobe along the occluded/non-occluded parenchyma's demarcation line. After sacrifice, the tissues were formalinfixed, and the plasma was stored at $-80{ }^{\circ} \mathrm{C}$ for subsequent 
analysis. Liver regeneration was measured in 5 animals per group at each time point and calculated using the following formula: right middle lobe (RML) weight/body weight $(\mathrm{BW}) \times 100 \%$.

\section{Histology}

Liver tissues were immersed in $4 \%$ formaldehyde, embedded, sectioned, gradient dehydrated, stained with hematoxylin-eosin (HE) or Sirius red, or stained for immunohistochemistry (IHC). The ratio of Ki-67-positive hepatocytes was calculated randomly in 4 visual fields $(\times 200)$ using Image-Pro Plus 5.1 (Media Cybernetics, USA), and the results were presented as a proliferation index (PI).

\section{Quantitative real-time polymerase chain reaction (PCR)}

Total RNA was isolated from cultured cells or frozen tissue using TRIzol reagent (Invitrogen, California, USA). Total RNA $(1 \mu \mathrm{g})$ was subjected to reverse transcription using a reverse transcription kit (Yeason, Shanghai, China). Quantitative real-time PCR was conducted using a Bio-Rad CFX96 system (Bio-Rad, Hercules, CA, USA) with SYBR Green to determine the mRNA levels of genes of interest. Expression levels were normalized to the expression of GAPDH. The primers are listed in Table S1.

\section{Western blotting}

Standard western blot assays were performed to analyze protein expression, as previously described. Briefly, the samples were treated with lysis buffer, and proteins were separated on a 10-15\% SDS-PAGE gel, then transferred onto PVDF membranes (Millipore, Billerica, MA, USA). After the membranes were blocked, they were incubated with appropriate dilutions of specific primary antibodies overnight. The blots were incubated with horseradish peroxidase (HRP)-conjugated secondary antibodies and visualized using the ECL system (Thermo Fisher Scientific, Rochester, NY, USA).

\section{Cell culture and functional experiments}

The hepatic cell line AML12 was obtained from Shanghai Advanced Research Institute, Chinese Academy of Sciences (Shanghai, China). AML12 cells were cultured in Dulbecco's modified Eagle's medium (DMEM; Gibco BRL, Rockville, MD) with $10 \%$ fetal bovine serum in a $5 \% \mathrm{CO}_{2}$ humidified incubator at $37^{\circ} \mathrm{C}$. The final concentration of transforming growth factor beta 1 (TGF- $\beta 1$ ) in AML 12 cells was $10 \mu \mathrm{g} / \mathrm{L}$ (24 hours). Functional experiments were performed according to the manufacturer's instructions (Tables S1,S2).

\section{Statistical analysis}

Data were expressed as the mean and standard deviation, both of which were compared with Student's t-tests. A twotailed $\mathrm{P}$ value lower than 0.05 was defined as statistically significant. Statistical analysis in this study was performed using SPSS, version 22.0 for Windows (IBM Corporation, Armonk, NY).

\section{Results}

\section{Inbibition of ALPPS-induced regeneration in the TAA- induced fibrosis model}

The schedule of TAA and phosphate-buffered saline (PBS) treatment is shown in Figure $1 A$. Diffuse nodules were observed on the surface of TAA-treated livers (Figure S1B). The deposition of collagenous fibers and activation of hepatic stellate cells (HSCs) were confirmed by HE staining, Sirius red staining, and $\alpha$-SMA staining (Figure $1 B$ ).

The TAA-treated group's mortality was $20 \%$ at postoperative day 2 and $40 \%$ at postoperative day 7 (Figure $\mathrm{S} 1 \mathrm{C}$ ). The $\mathrm{RML} / \mathrm{BW}$ ratio was comparable between the 2 groups at baseline $(\mathrm{P}=0.331)$. After ALPPS, the proliferation of FLRs in the TAA-treated and PBStreated groups was respectively $0.0138 \pm 0.0006$ and $0.0123 \pm 0.0017$ at postoperative day 2 and $0.0236 \pm 0.0015$ and $0.0160 \pm 0.0015$ at postoperative day 7 , which suggested that FLR hypertrophy was significantly better in the PBStreated group than in the TAA-treated group $(\mathrm{P}=0.027$ at postoperative day 2 and $\mathrm{P}<0.001$ at postoperative day 7 ; Figure 1C). Increased cyclinD1 expression and decreased p21 expression indicated accelerated proliferation of FLRs in non-fibrotic mice (Figure 1D). Histologically, the number of Ki-67-positive hepatocytes in the PBS-treated group increased distinctly at day 2 and was superior to that in the TAA-induced fibrosis group (Figure 1E).

\section{Mitochondrial dysfunction during ALPPS in livers with TAA-induced fibrosis}

As mentioned previously, several pathways (e.g., 
A

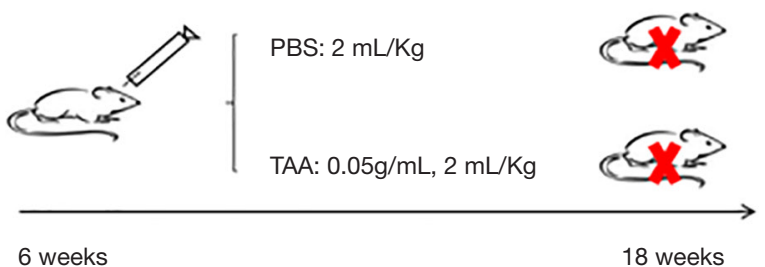

B
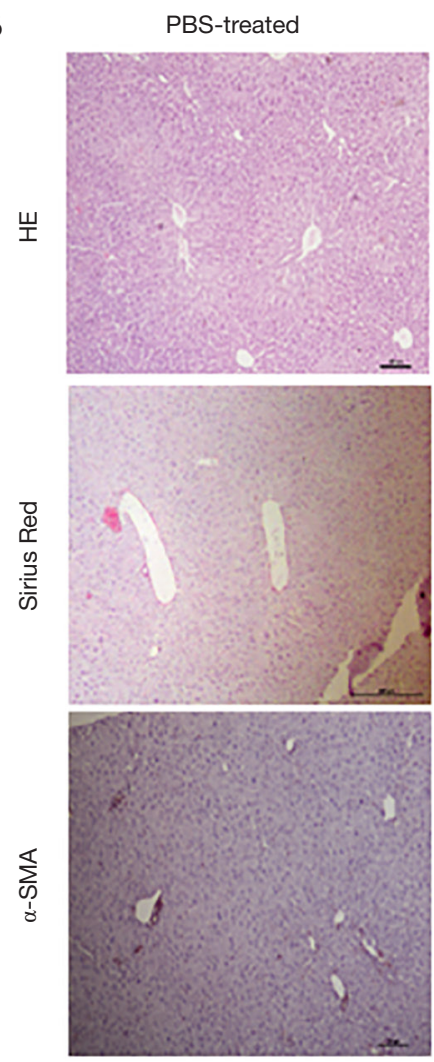

D

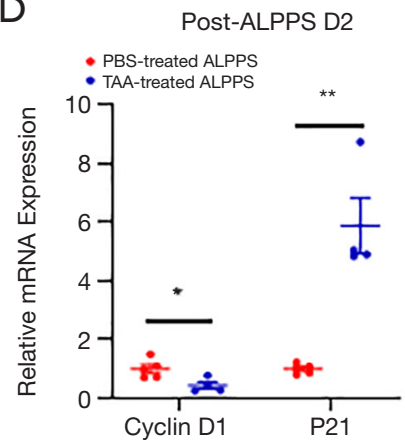

TAA-treated
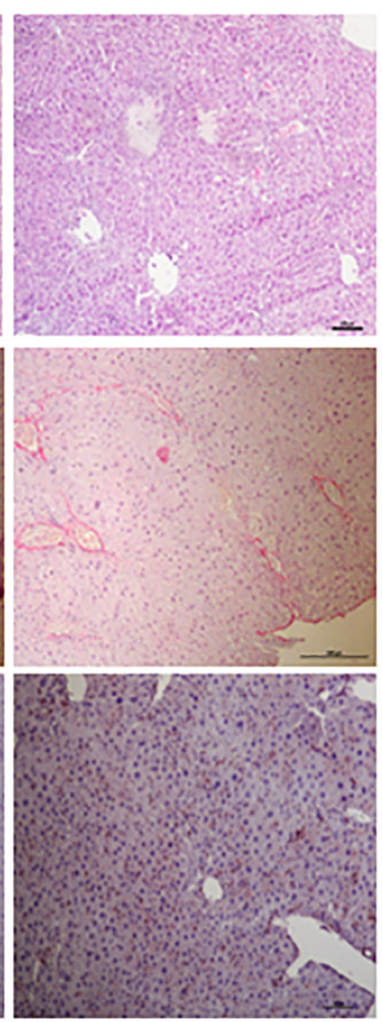

Post-ALPPS D7

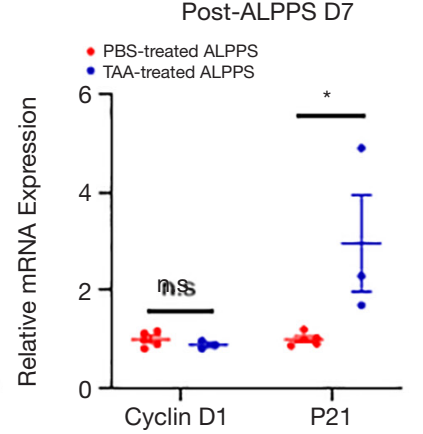

C

PBS-treated ALPPS

- TAA-treated ALPPS
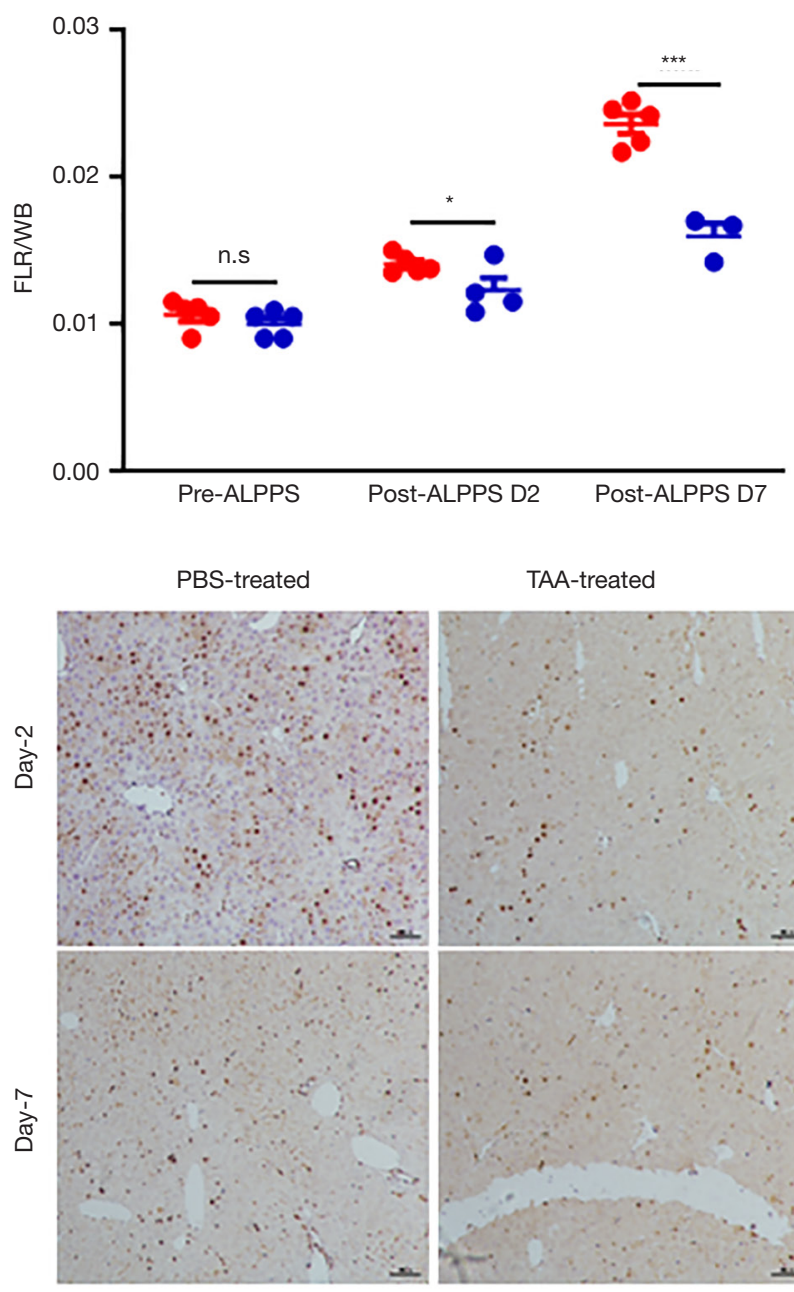

$\mathrm{E}$

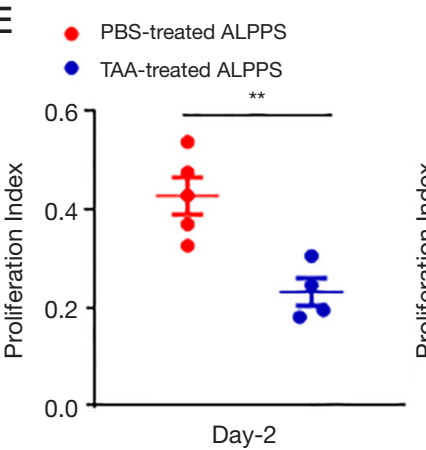

TAA-treated

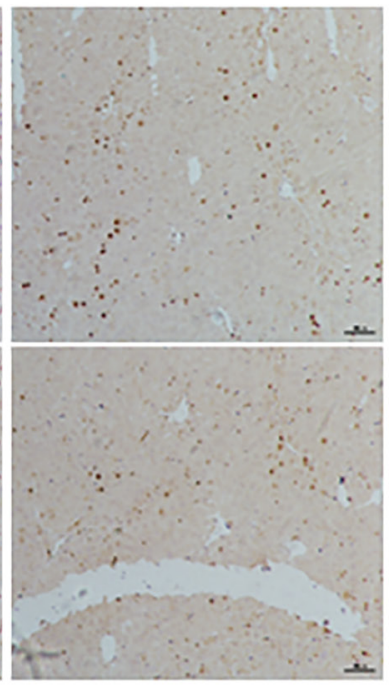

- PBS-treated ALPPS

- TAA-treated ALPPS

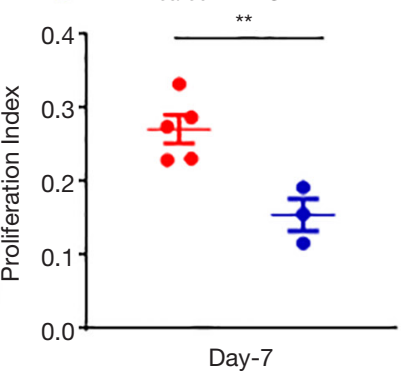

Figure 1 Liver regeneration in the TAA-induced model. (A) Flow chart of the TAA-induced fibrosis model; (B) histological evaluation by IHC $(\times 100)$ of the TAA-induced fibrosis model; (C) proliferation curves of FLRs in mice with PBS-treated or TAA-induced livers; (D) mRNA expression of cyclinD1 and $\mathrm{p} 21$; (E) IHC of Ki-67 and proliferation index. ${ }^{*} \mathrm{P}<0.05,{ }^{*} \mathrm{P}<0.01$, and ${ }^{* * *} \mathrm{P}<0.001$. TAA, thioacetamide; PBS, phosphate buffered-saline; FLR, future liver remnant; RML, right middle lobe; IHC, immunohistochemistry; $\mathrm{n}=5$ mice for each condition. 
inflammatory pathways, the IHH/Gli1 pathway, growth factor-associated pathways, the mTOR pathway, and mitochondria-related pathways) have been reported to be implicated in ALPPS-induced regeneration. PCR was initially performed to screen potential targets that are responsible for the impaired proliferative capacity associated with ALPPS in livers with fibrosis (Figure $2 A$ and Figure S2). Compared with that of the PBS-treated group, the inflammatory response was significantly increased in TAAinduced fibrotic livers before and after ALPPS. Similarly, TGF- $\beta 1$ expression was also increased in response to TAA treatment. Also, the downregulation of PGC1 $\alpha$ indicated impairment in mitochondria-related pathways in ALPPSinduced regeneration. This study, therefore, focused on mitochondrial dysfunction in the process of regeneration after the ALPPS procedure.

Classic markers associated with mitochondrial function were initially determined further to investigate the roles of mitochondria-related pathways during ALPPS. PGC1 $\alpha$ protein was significantly decreased in TAA-induced fibrotic livers at baseline and at days 2 and 7 after ALPPS $(\mathrm{P}=0.002, \mathrm{P}<0.001$, and $\mathrm{P}=0.014$, respectively; Figure $2 B)$. Similarly, mitochondria-associated gene expression was downregulated in TAA-treated livers, which suggested mitochondrial dysfunction throughout the regenerative process (Figure 2C). As expected, the reduced production of ATP in livers with TAA-induced fibrosis indicated a deficiency in energy production (Figure 2D). Elevated malondialdehyde (MDA) levels represented reactive oxygen species' accumulation, membrane lipid peroxidation, and a disturbance in intracellular energy metabolism (Figure 2E). Thus, these results suggested that mitochondrial dysfunction in TAA-induced fibrotic livers could not meet the energy requirements of rapid proliferation.

\section{Mitochondrial dysfunction in TGF- $\beta 1$-treated AML12 cells}

To further investigate this theory, mitochondrial dysfunction was evaluated in the TGF- $\beta 1$-treated cellular fibrosis model. Mitochondrial membrane potential was analyzed by determining the ratio of JC-1 monomers and aggregates and revealed apparent uncoupling of the mitochondrial membrane potential in TGF- $\beta 1$-treated AML12 cells (Figure 3A). Increased absorbance of MitoSox and increased production of MDA indicated a disturbance in mitochondrial oxygen consumption after TGF- $\beta 1$ treatment (Figure 3B). We then found distinct mitochondrial dysfunction by detecting mitochondria-associated RNA expression and ATP production (Figure $3 C, D$ ) that led to reduced viability and survival in the TGF- $\beta 1$-treated group (Figure 3E,F).

\section{The ALPPS-induced proliferation of FLRs was attenuated in livers with $\mathrm{CCl}_{4}$-induced fibrosis due to mitochondrial dysfunction}

To further validate the involvement of mitochondrial dysfunction in rapid regeneration, a $\mathrm{CCl}_{4}$-induced fibrosis model was established (Figure 4A). Typically, disseminated nodules were present on the surface of $\mathrm{CCl}_{4}$-treated livers compared to oil-treated livers (Figure S1B). HE staining, Sirius red staining and $\alpha$-SMA staining revealed many collagenous fiber deposits and activation of HSCs (Figure 4B). Downregulation of PGC1 $\alpha$ and mitochondriarelated molecules further demonstrated impairment of mitochondrial pathways (Figure 4C,D). Consequently, ATP production in $\mathrm{CCl}_{4}$-challenged livers was significantly less than that in oil-challenged livers $(\mathrm{P}=0.004$; Figure $4 E)$. In contrast, MDA levels were significantly upregulated in livers with $\mathrm{CCl}_{4}$-induced fibrosis $(\mathrm{P}=0.021$; Figure $4 F)$.

The mortality rate was analyzed, and only 1 mouse in the $\mathrm{CCl}_{4}$-treated group died on day 7 after the ALPPS procedure. Regeneration was also analyzed, and no differences in FLRs were observed between the groups at baseline. The proliferation of FLRs at day 2 after ALPPS in the oil-treated group was $0.0144 \pm 0.0026$, which was significantly better than $0.0119 \pm 0.0004$ in the $\mathrm{CCl}_{4^{-}}$ treated group $(\mathrm{P}=0.043)$. On a postoperative day 7 , the proliferation of FLRs in the oil-treated group reached $0.0239 \pm 0.0004$, which was better than $0.0163 \pm 0.0015$ in the $\mathrm{CCl}_{4}$-treated group $(\mathrm{P}<0.001$; Figure $5 \mathrm{~A})$. Likewise, reduced expression of cyclinD1 and increased expression of p21 revealed less regeneration in livers with $\mathrm{CCl}_{4}$-induced fibrosis (Figure 5B). The difference in regeneration was also validated histologically, as the PI of the oil-treated group after ALPPS was significantly higher than that of the $\mathrm{CCl}_{4}$ treated group $(\mathrm{P}<0.001$ at day 2 and $\mathrm{P}=0.006$ at day 7 ; Figure (C). Therefore, mitochondrial dysfunction in livers with $\mathrm{CCl}_{4}$-induced fibrosis contributed to inferior FLR 
A

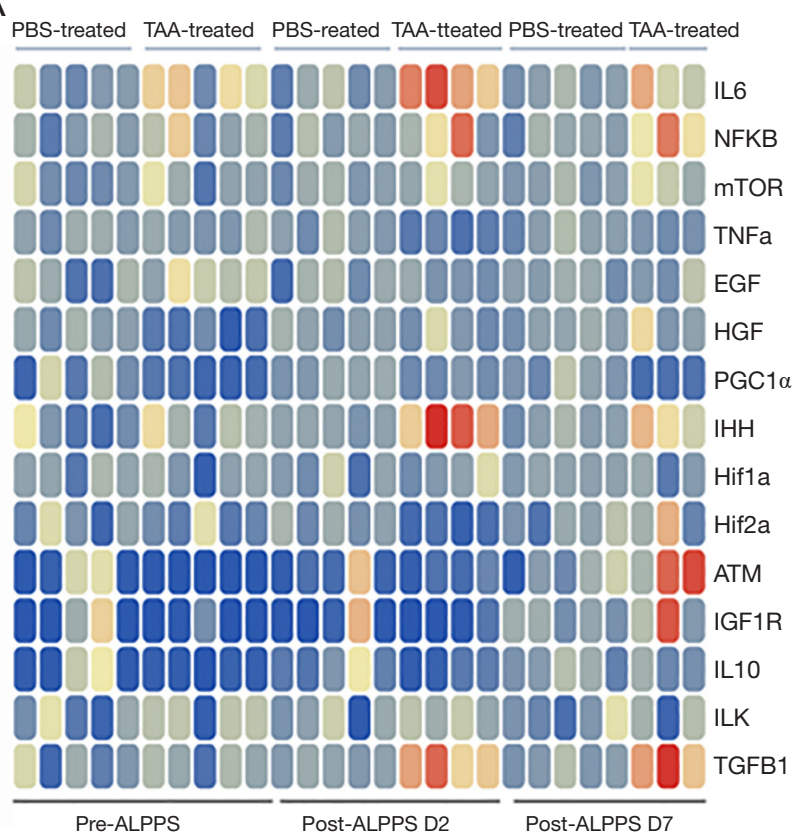

C

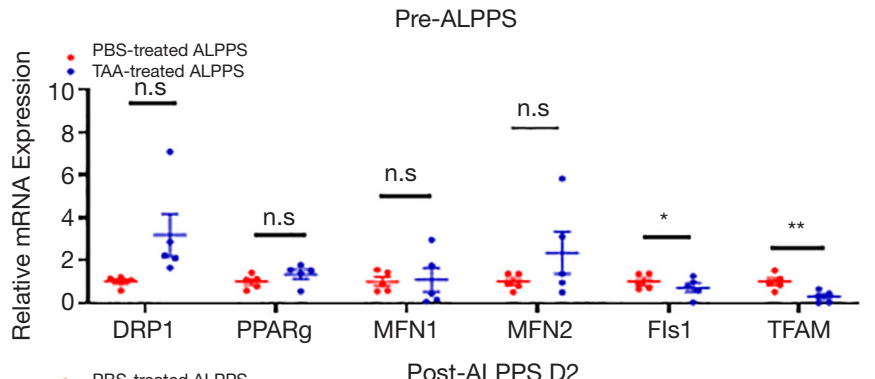

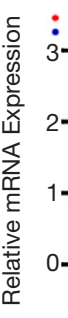

음

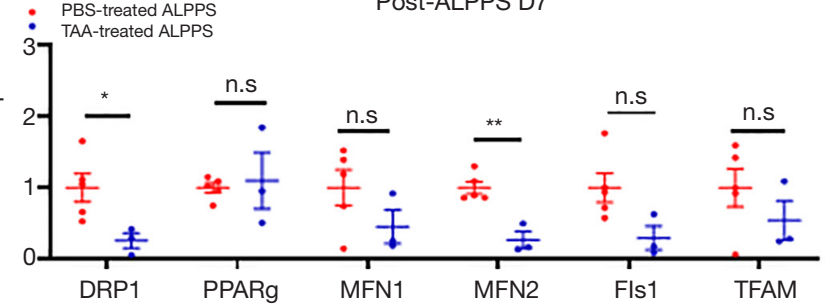

B
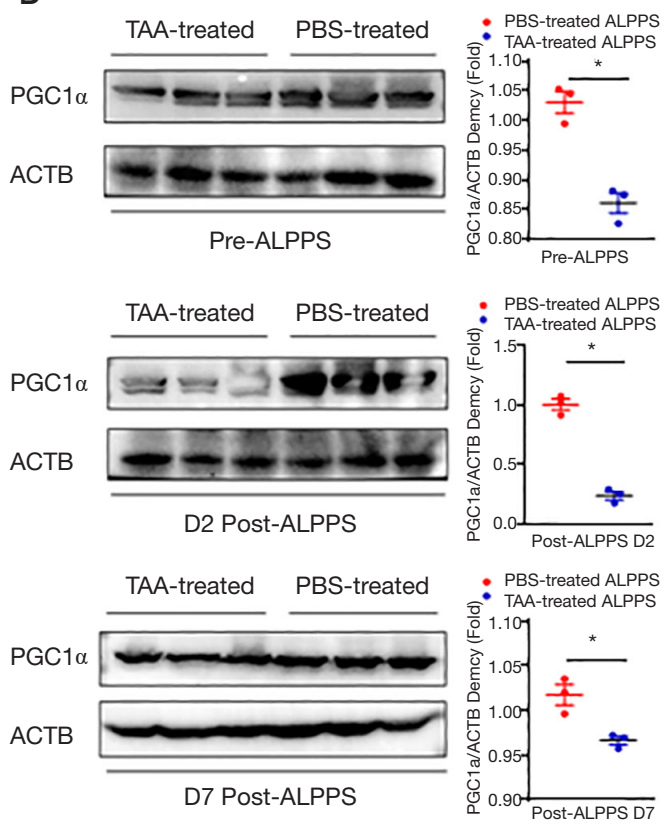

$\mathrm{E}$
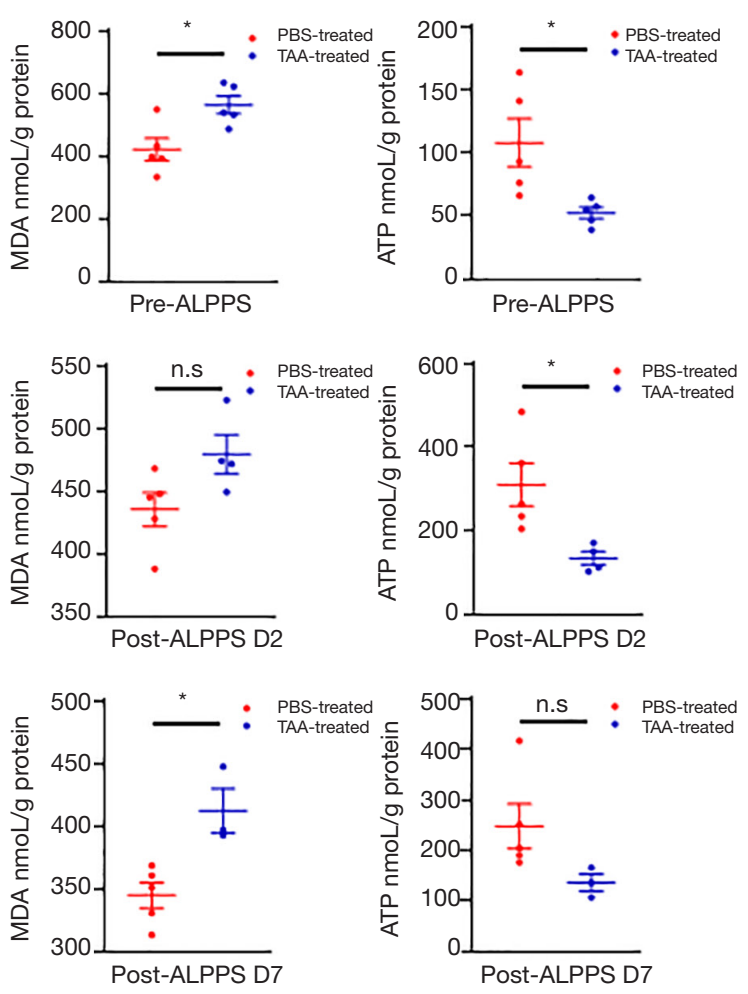

Figure 2 Mitochondrial dysfunction during ALPPS in livers with TAA-induced fibrosis. (A) Several regenerative pathways during ALPPS in PBS- or TAA-treated models; (B) PGC1 $\alpha$ expression in PBS- or TAA-treated mice during ALPPS; (C) Mitochondria-associated gene expression in PBS- or TAA-treated mice during ALPPS; (D,E) MDA and ATP production in PBS- or TAA-treated mice during ALPPS. ${ }^{*} \mathrm{P}<0.05,{ }^{*} \mathrm{P}<0.01$. TAA, thioacetamide; PBS, phosphate buffered-saline; MDA, malondialdehyde; ALPPS, associating liver artition and portal vein ligation for staged hepatectomy; $\mathrm{n}=5$ mice for each condition. 
A

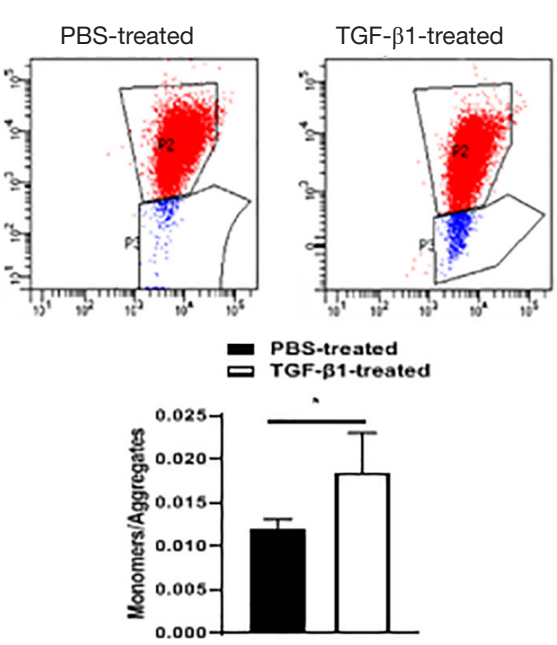

C

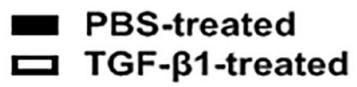

B
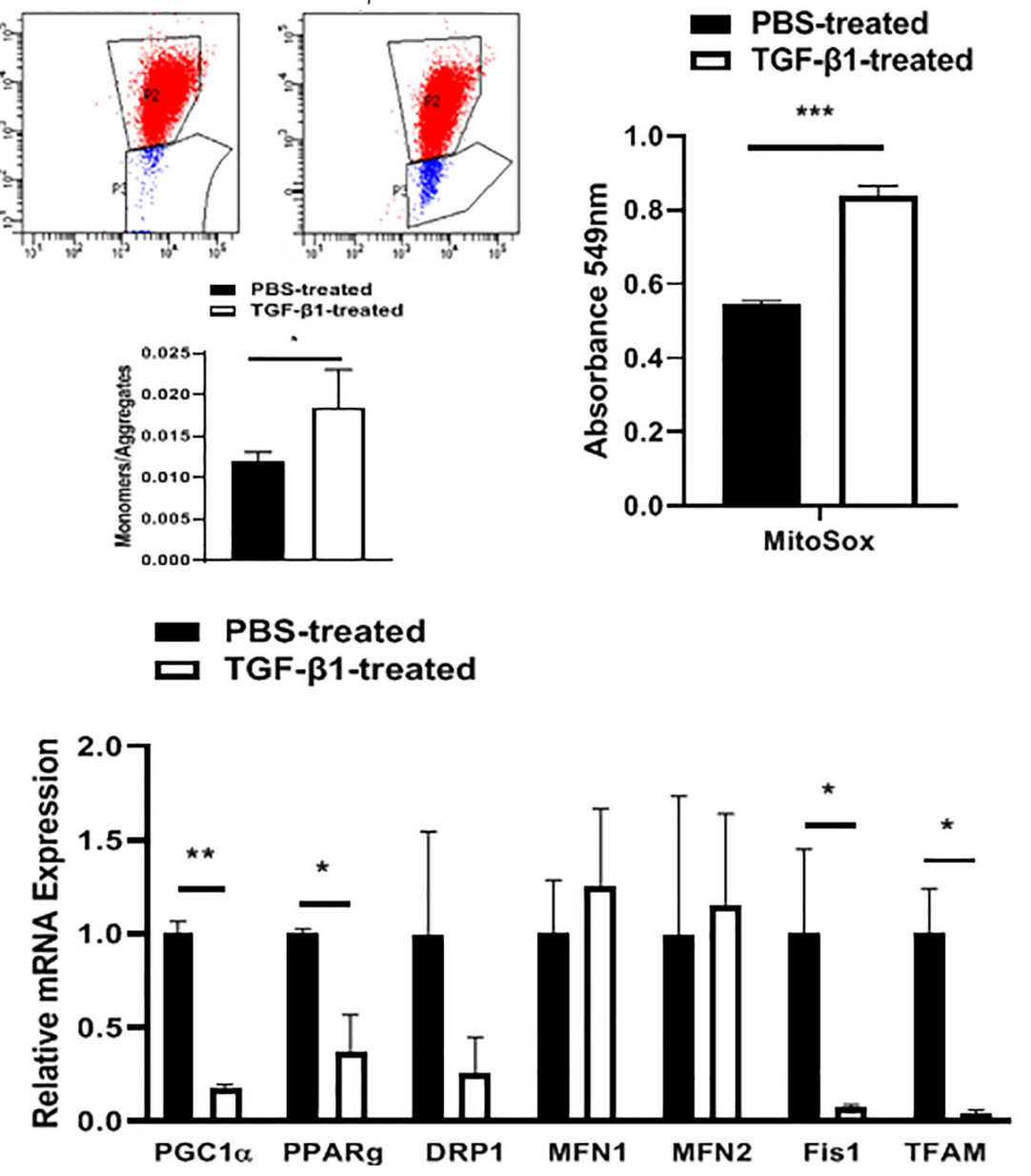

PBS-treated

口 TGF- $\beta 1$-treated
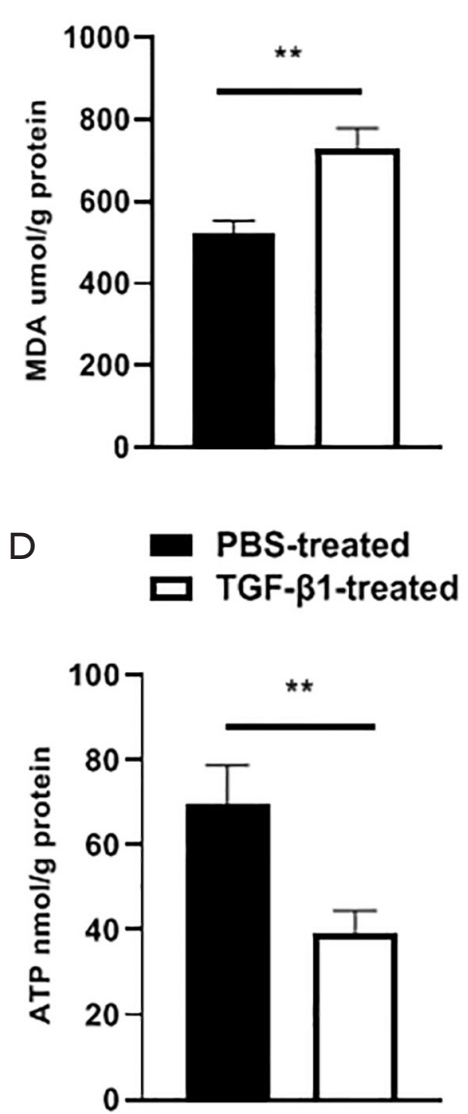

$E$

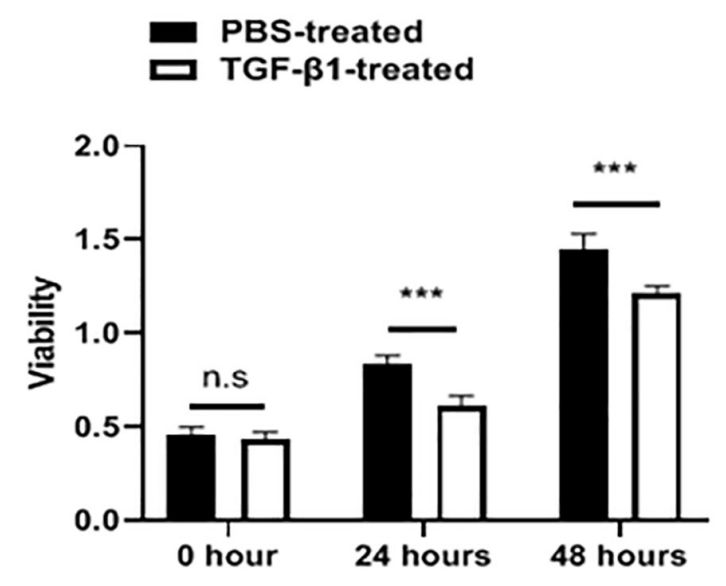

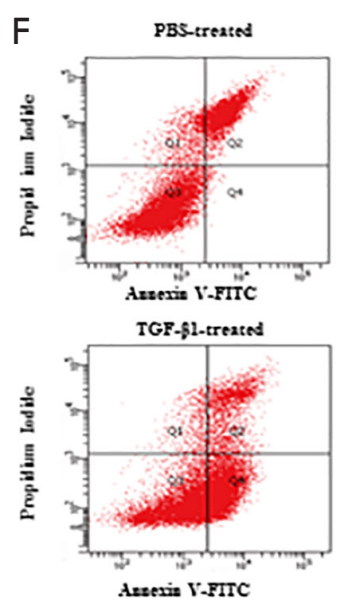

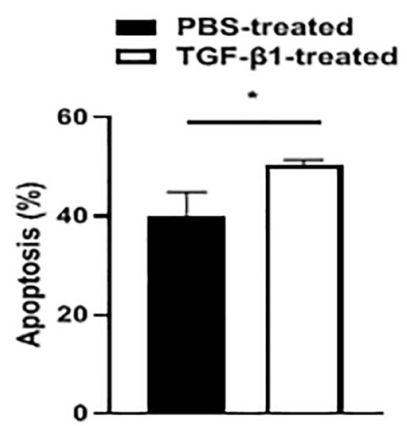

Figure 3 Mitochondrial dysfunction in TGF- $\beta 1$-treated AML12 cells. (A) Mitochondrial membrane potential (JC-1); (B) mitoSox and MDA detection; (C) mitochondria-associated gene expression; (D) ATP production; (E) cell viability; (F) apoptosis. ${ }^{*} \mathrm{P}<0.05$, ${ }^{* *} \mathrm{P}<0.01$, and ${ }^{* * *} \mathrm{P}<0.001$. TGF- $\beta 1$, transforming growth factor beta 1 ; PBS, phosphate buffered-saline; MDA, malondialdehyde. 
A

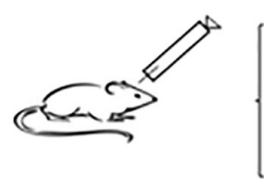

Oil: $100 \%, 5 \mathrm{~mL} / \mathrm{Kg}$

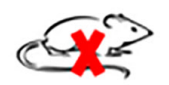
$\mathrm{CCL}_{4}: 20 \% \mathrm{CCL}_{4}$
$\left(\mathrm{CCL}_{4}: \mathrm{Oil}=1: 4\right) 5 \mathrm{~mL} / \mathrm{Kg}$

6 weeks

B

Oil-treated
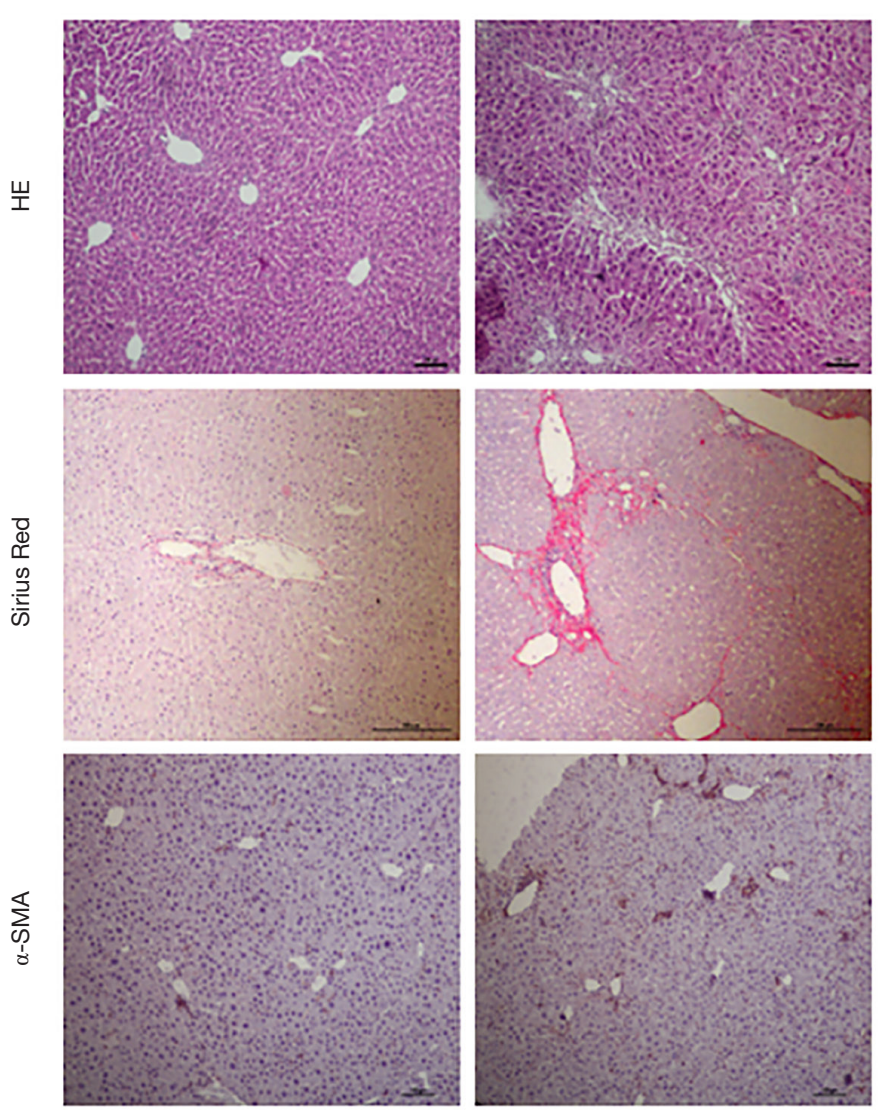

D

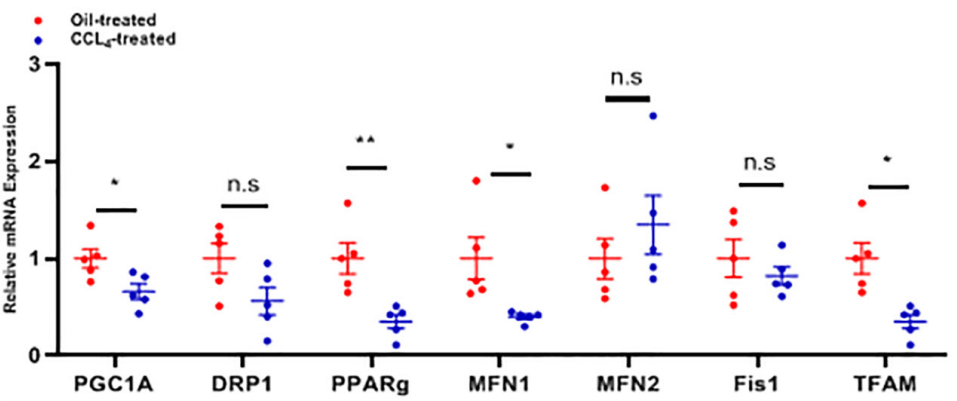

$\mathrm{CCL}_{4}$-treated

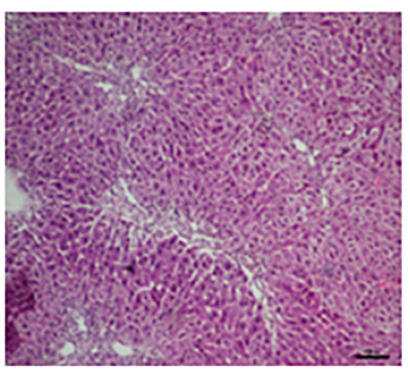

ACTB

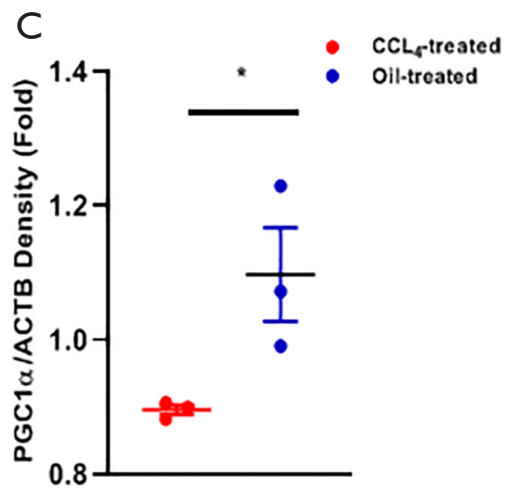

E

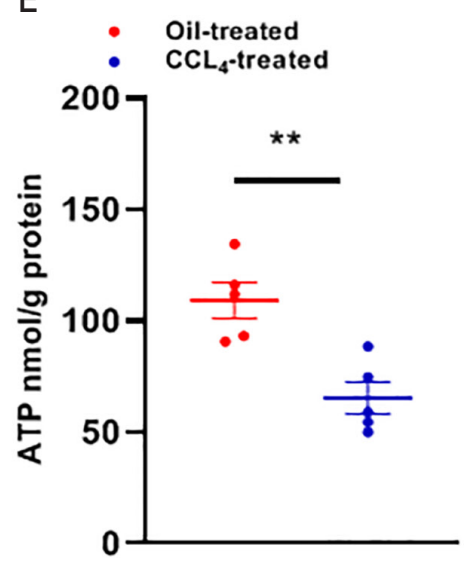

F

- Oil-treated

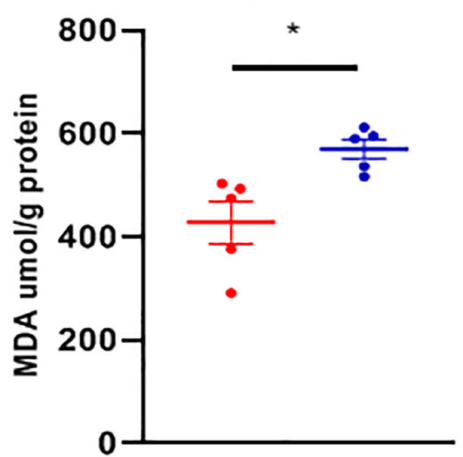

Figure 4 Mitochondrial dysfunction in livers with CCl4-induced fibrosis. (A) Flow chart of the CCl4-induced fibrosis model; (B) Histological evaluation by immunohistochemistry $(\times 100)$ of the CCl4-induced fibrosis model; (C) PGC1 $\alpha$ expression in oil- or CCl4-treated mice; (D) Mitochondria-associated gene expression in oil- or CCl4-treated mice; (E) MDA detection in oil- or CCl4-treated mice; (F) ATP production in oilor CCl4-treated mice. ${ }^{*} \mathrm{P}<0.05,{ }^{* *} \mathrm{P}<0.01$. CCL4, carbon tetrachloride; MDA, malondialdehyde; $\mathrm{n}=5$ mice for each condition. 
A

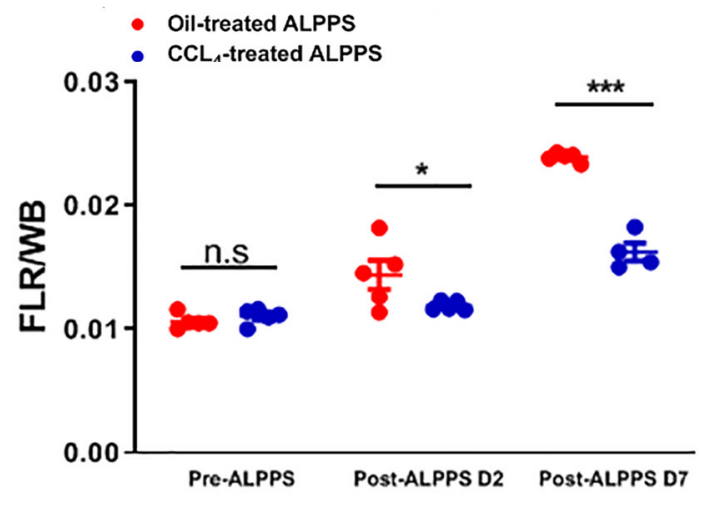

B

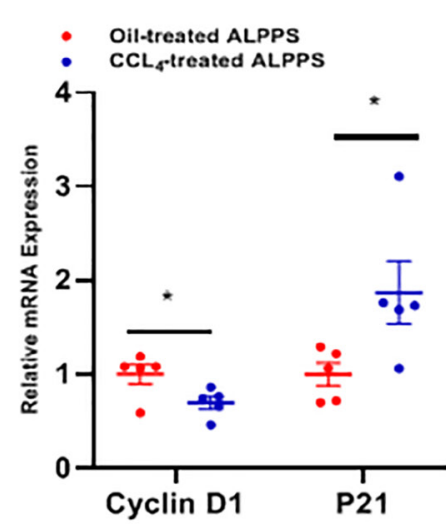

Post-ALPPS D7

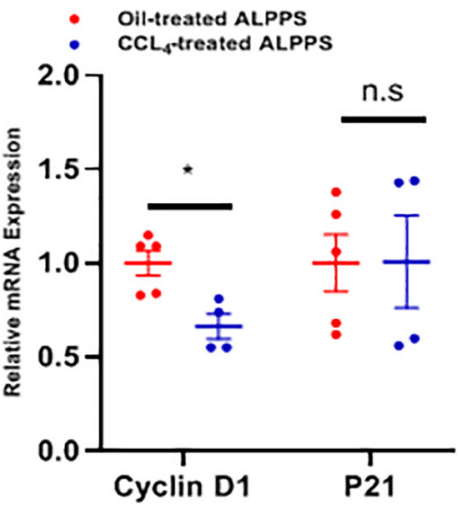

C
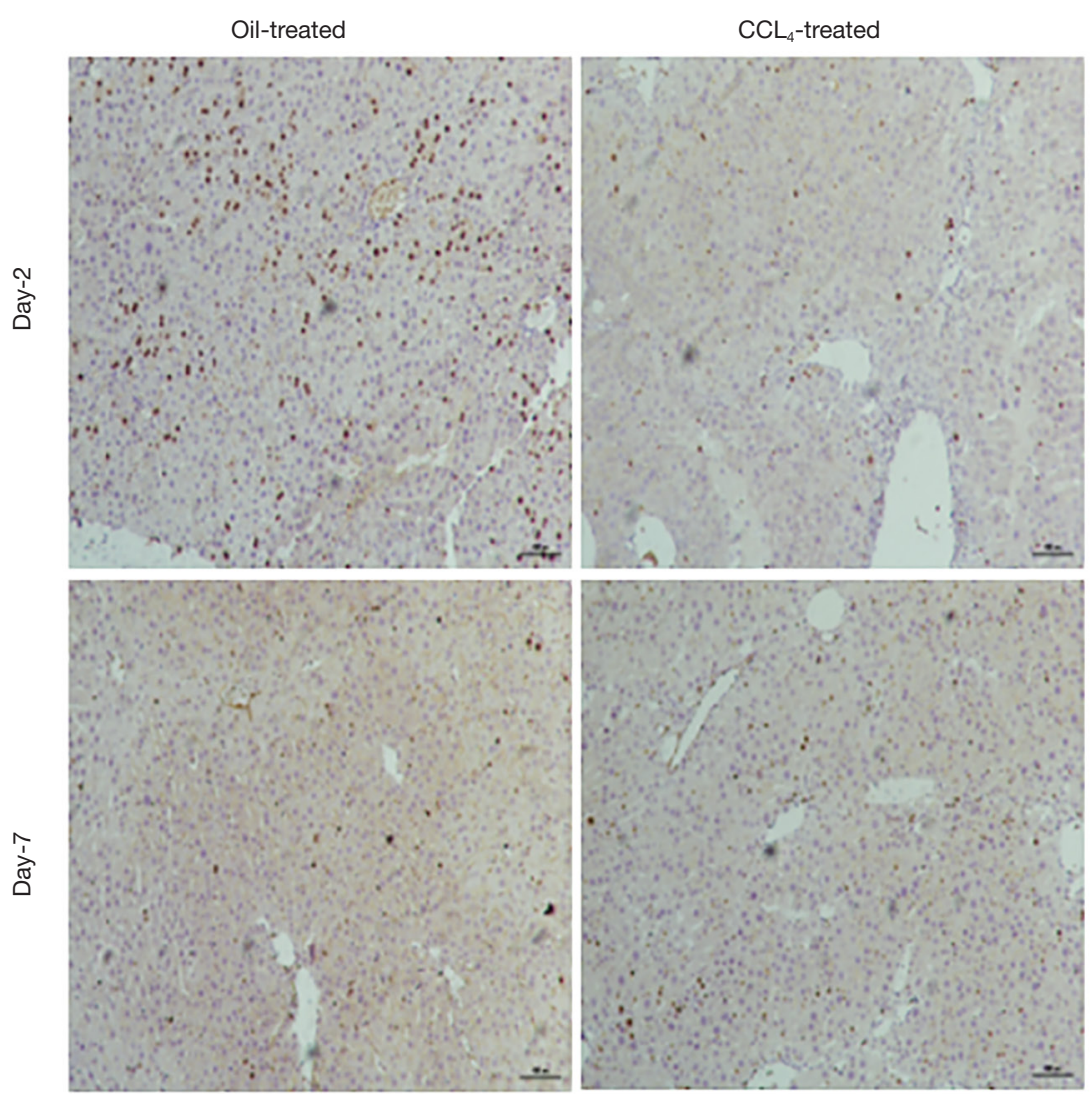

- Oil-treated ALPPS

- $\mathrm{CCL}_{4}$-treated ALPPS

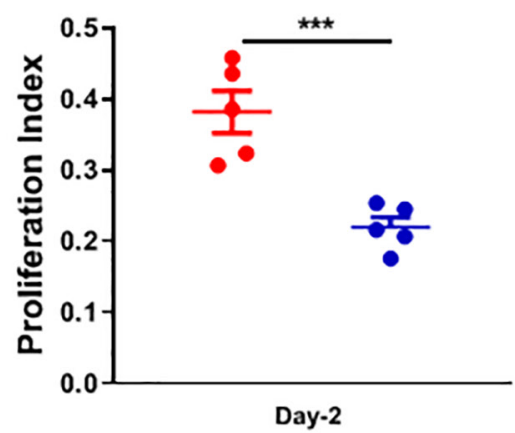

- Oil-treated ALPPS

- $\mathrm{CCL}_{4}$-treated ALPPS

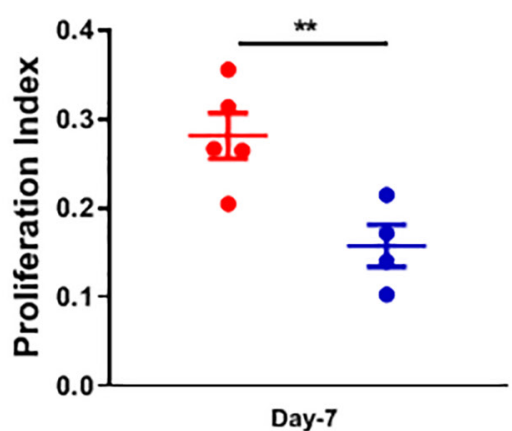

Figure 5 ALPPS-induced proliferation of FLRs was attenuated in livers with $\mathrm{CCl}_{4}$-induced fibrosis. (A) Proliferation curves of FLRs in mice with oil-treated or $\mathrm{CCl}_{4}$-induced livers; (B) mRNA expression of cyclinD1 and p21; (C) IHC (×100) of Ki-67 and proliferation index. ${ }^{*} \mathrm{P}<0.05,{ }^{*} \mathrm{P}<0.01$, and ${ }^{* * *} \mathrm{P}<0.001$. $\mathrm{CCl}_{4}$, carbon tetrachloride; FLR, future liver remnant; RML, right middle lobe; ALPPS, associating liver partition and portal vein ligation for staged hepatectomy; IHC, immunohistochemistry; $\mathrm{n}=5$ mice for each condition. 
proliferation after ALPPS.

\section{ALPPS in the clinic}

Due to ALPPS samples' rarity in the clinic, we preliminarily compared mitochondrial function and capacity for ALPPSinduced regeneration in 2 hepatocellular carcinoma patients. Compared to the non-fibrotic patient (male, 69 years old), the downregulation of several crucial molecules that mediate mitochondrial energy metabolism was observed in the fibrotic patient (male, 32 years old; Figure $6 A$ ). The FLRs in the fibrotic and non-fibrotic patients were $345.6 \mathrm{~mL}(27.9 \%)$ and $300.4 \mathrm{ml}(23.7 \%)$, respectively. After the ALPPS stage I, the FLRs in the fibrotic and non-fibrotic patients increased to $388.5 \mathrm{~mL}$ $(31.3 \%)$ and $653.3 \mathrm{~mL}(51.5 \%)$, respectively (Figure $6 B$ ). Also, liver function recovery was significantly prolonged in the patient with fibrosis (Figure 6C).

\section{Discussion}

To date, the underlying mechanism of ALPPS-induced rapid liver regeneration remains poorly documented in patients with a history of fibrosis. Because experimental models are easily standardized to yield better reproducibility, they are preferred when assessing feasibility and investigating mechanisms of such high-risk events. To the best of our knowledge, no basic research on ALPPS has been conducted in mice with toxin-induced fibrosis. Consistent with our previous study suggesting that fibrosis attenuated ALPPS-induced regeneration in a rat model (6), our current study showed that ALPPS-induced regeneration was significantly attenuated in 2 established fibrosis models.

Although preliminary studies have shown that mitochondrial function, hypoxia signals, and the pathways above are involved in ALPPS-induced regeneration, there is a lack of robust evidence to support the causality (7-10,15). A deeper understanding of the activation of HSCs and the JNK1/IHH axis has been demonstrated as the first example of an ALPPS-induced molecular event associated with unprecedented regenerative acceleration $(7,16)$. To explore the key pathway that regulates ALPPS-induced regeneration in livers with fibrosis, preliminary target screening in a TAA-induced fibrosis model was performed, and a mitochondria-related pathway was identified. Based on the fact that mitochondrial function alterations impact cellular metabolism, mitochondrial dysfunction could ultimately affect numerous biological processes, including regeneration (17-19). Increasing evidence suggests that functional and structural abnormalities in hepatocyte mitochondria lead to oxidative phosphorylation impairment and elevated production of reactive oxygen species (20). Thus, we found that impaired mitochondrial function attenuated rapid liver regeneration in vitro and in a $\mathrm{CCl}_{4}^{-}$ induced fibrosis model.

As previously shown, ALPPS-induced liver regeneration is a complex process involving parenchymal cells (e.g., hepatocytes, biliary epithelial cells, and hepatic progenitor cells) and non-parenchymal cells (e.g., Kupffer cells, HSCs, and liver sinusoidal endothelial cells) (21-25). Since HSCinduced IHH promotes liver regeneration, the definitive role of HSCs in ALPPS-mediated promotion of hepatic regeneration has therefore long been of interest $(7,26)$. Compared with the mild activation of HSCs induced by the ALPPS procedure, HSC activation appears to be more drastic in the context of toxin-induced fibrosis. Different patterns of HSC activity may result in diverse effects on ALPPS-induced liver regeneration $(27,28)$. Also, the roles of biliary epithelial cells and other non-parenchymal cells are not fully understood.

Despite increasing reports of ALPPS cases, the feasibility of ALPPS in livers with fibrosis or cirrhosis has not been fully addressed. Previous studies have indicated that the severity of fibrosis is negatively related to the capacity for ALPPS-induced regeneration. As we revealed that mitochondrial dysfunction led to inferior regeneration in livers with toxin-induced fibrosis, new drugs targeting mitochondrial dysfunction might therefore improve the capacity for ALPPS-induced regeneration in livers with fibrosis or cirrhosis in clinical settings.

\section{Conclusions}

In conclusion, this study uncovered mitochondrial dysfunction during ALPPS-induced regeneration in livers with fibrosis, leading to new opportunities to accelerate regeneration. However, the mechanism by which mitochondrial dysfunction inhibits ALPPS-induced proliferation in livers with fibrosis should be investigated in more human samples. Since a variety of factors causes liver fibrosis (e.g., hepatitis virus infection, cholestasis, alcohol abuse, and chemotherapy) in clinical settings, it remains 
A

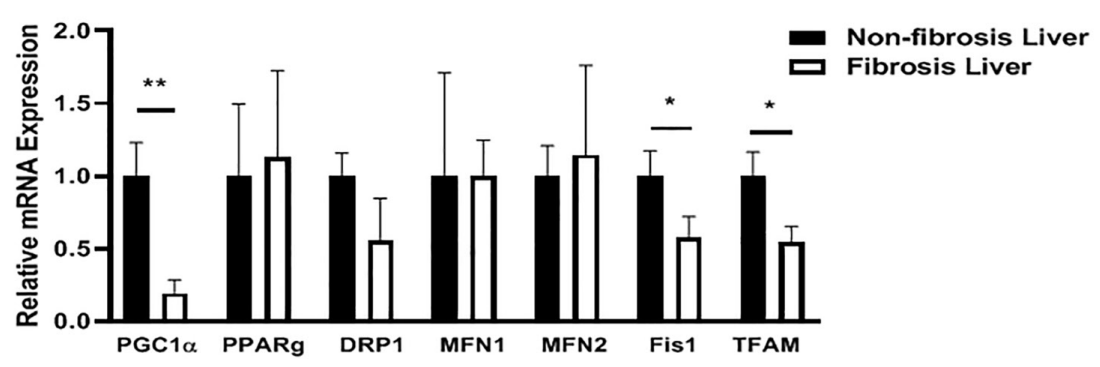

B
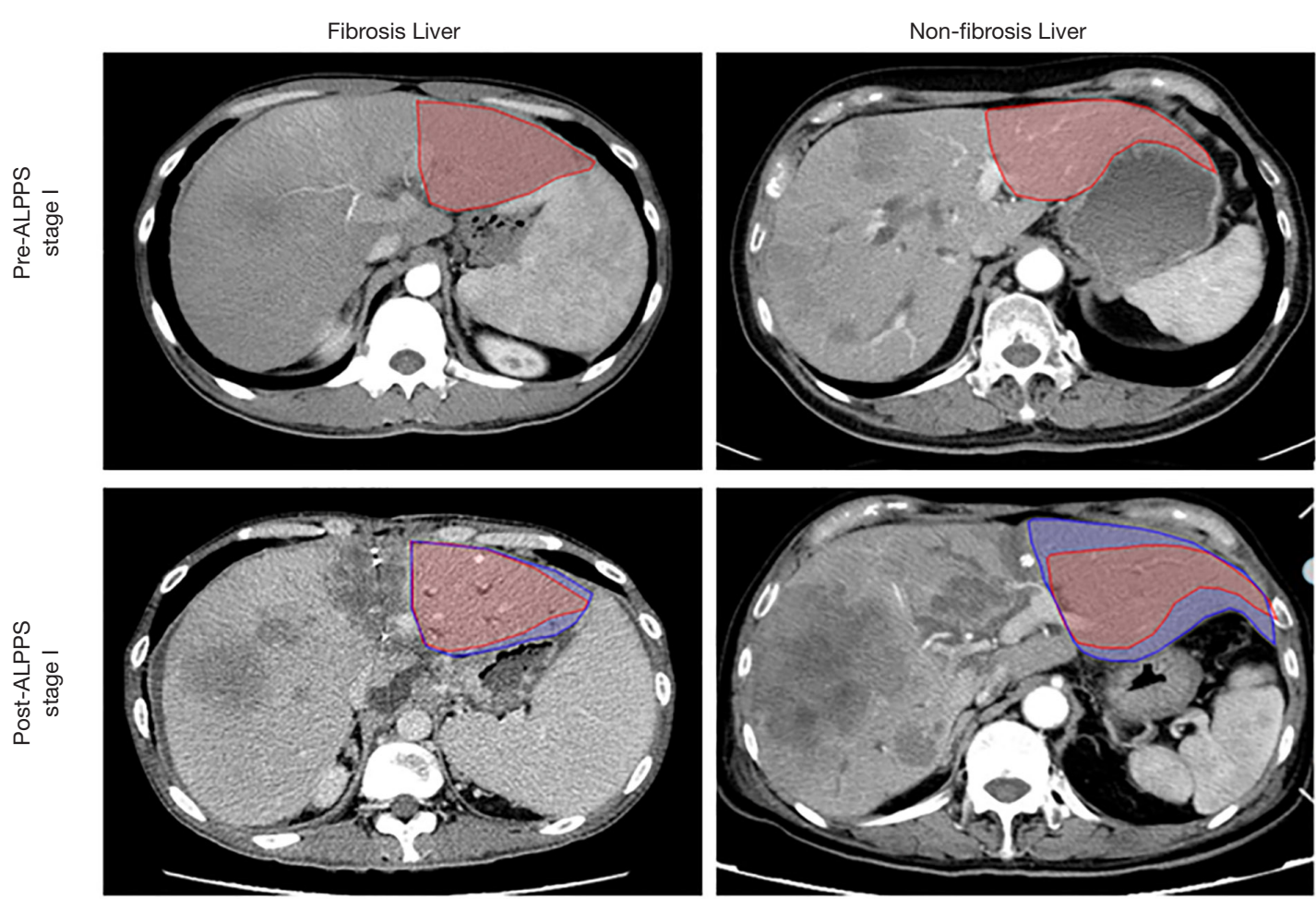

C
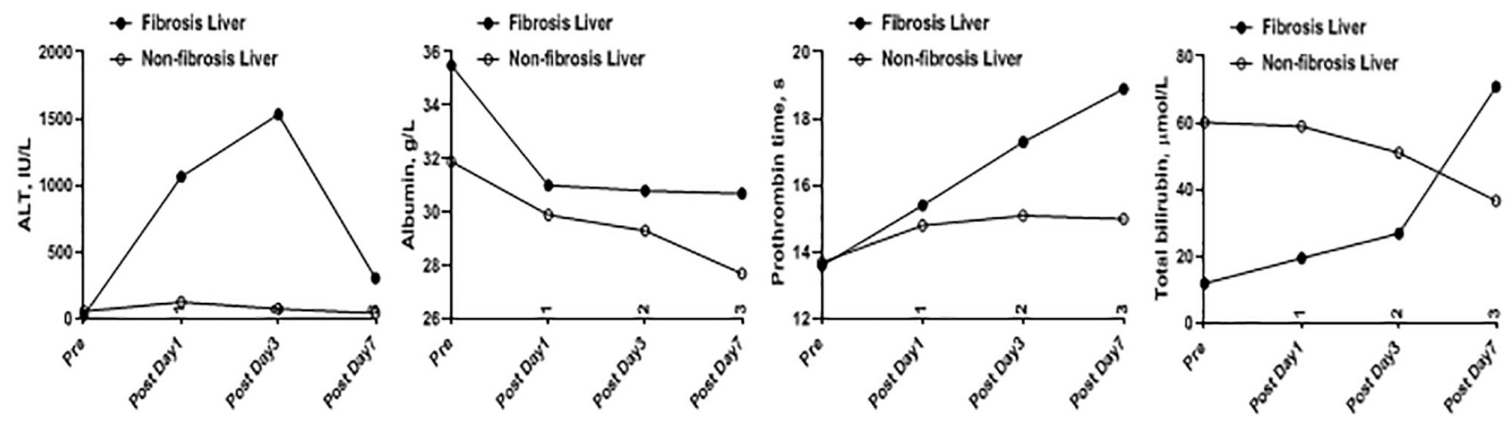

Figure 6 ALPPS patients in the clinic. (A) Mitochondria-associated gene expression in a fibrosis patient and a non-fibrosis patient; (B) Volumetric evaluation before and after ALPPS stage I by CT scan. The red area represents the proper FLR and the blue area represents the increased FLR; (C) Liver function after ALPPS stage I. ${ }^{*} \mathrm{P}<0.05,{ }^{* *} \mathrm{P}<0.01$. ALT, alanine transaminase; FLR, future liver remnant; ALPPS, associating liver partition and portal vein ligation for staged hepatectomy. 
unclear whether these findings should be validated under different conditions. Therefore, further studies in humans are needed in the future.

\section{Acknowledgments}

Funding: This study was supported by the Natural Science Foundation of Zhejiang Province (Grant No. LY15H030009).

\section{Footnote}

Reporting Checklist: The authors have completed the ARRIVE reporting checklist. Available at http://dx.doi. org/10.21037/atm-20-4639

Data Sharing Statement: Available at http://dx.doi. org/10.21037/atm-20-4639

Conflicts of Interest: All authors have completed the ICMJE uniform disclosure form (available at http://dx.doi. org/10.21037/atm-20-4639). The authors have no conflicts of interest to declare.

Ethical Statement: The authors are accountable for all aspects of the work in ensuring that questions related to the accuracy or integrity of any part of the work are appropriately investigated and resolved. Experiments were performed under a project license (No. 11836) granted by the Animal Ethics Committee of Sir Run Run Shaw Hospital, Zhejiang University, China, in compliance with the Animal Ethics Committee of Sir Run Run Shaw Hospital's guidelines for the care and use of animals. The study was conducted in accordance with the Declaration of Helsinki (as revised in 2013). The study was approved by the Human Ethics Committee of Sir Run Run Shaw Hospital, Zhejiang University, China (No. 20180226-25) and informed consent was obtained from all individual participants.

Open Access Statement: This is an Open Access article distributed in accordance with the Creative Commons Attribution-NonCommercial-NoDerivs 4.0 International License (CC BY-NC-ND 4.0), which permits the noncommercial replication and distribution of the article with the strict proviso that no changes or edits are made and the original work is properly cited (including links to both the formal publication through the relevant DOI and the license). See: https://creativecommons.org/licenses/by-nc-nd/4.0/.

\section{References}

1. Olthof PB, Schnitzbauer AA, Schadde E. The HPB controversy of the decade: 2007-2017 - Ten years of ALPPS. Eur J Surg Oncol 2018;44:1624-7.

2. Schnitzbauer AA, Lang SA, Goessmann H, et al. Right portal vein ligation combined with in situ splitting induces rapid left lateral liver lobe hypertrophy enabling 2 -staged extended right hepatic resection in small-for-size settings. Ann Surg 2012;255:405-14.

3. Kawka M, Gall TMH, Jiao LR. Minimum invasive associating liver partition and portal vein ligation for staged hepatectomy. Laparosc Endosc Robot Surg 2020;3:1-5.

4. Linecker M, Björnsson B, Stavrou GA, et al. Risk Adjustment in ALPPS Is Associated With a Dramatic Decrease in Early Mortality and Morbidity. Ann Surg 2017;266:779-86.

5. Wang Z, Peng Y, Hu J, et al. Associating Liver Partition and Portal Vein Ligation for Staged Hepatectomy for Unresectable Hepatitis B Virus-related Hepatocellular Carcinoma: A Single Center Study of 45 Patients. Ann Surg 2020;271:534-41.

6. Yifan T, Ming X, Yifan W, et al. Hepatic regeneration by associating liver partition and portal vein ligation for staged hepatectomy (ALPPS) is feasible but attenuated in rat liver with thioacetamide-induced fibrosis. Surgery 2019;165:345-52.

7. Langiewicz M, Schlegel A, Saponara E, et al. Hedgehog pathway mediates early acceleration of liver regeneration induced by a novel two-staged hepatectomy in mice. J Hepatol. 2017;66:560-70.

8. Schlegel A, Lesurtel M, Melloul E, et al. ALPPS: from human to mice highlighting accelerated and novel mechanisms of liver regeneration. Ann Surg 2014;260:839-46.

9. Budai A, Horváth G, Tretter L, et al. Mitochondrial Function After Associating Liver Partition and Portal Vein Ligation for Staged Hepatectomy in an Experimental Model. Br J Surg 2019;106:120-31.

10. Borger P, Schneider M, Frick L, et al. Exploration of the Transcriptional Landscape of ALPPS Reveals the Pathways of Accelerated Liver Regeneration. Front Oncol 201;9:1206.

11. Sanz S, Pucilowska JB, Liu S, et al. Expression of insulinlike growth factor I by activated hepatic stellate cells reduces fibrogenesis and enhances regeneration after liver injury. Gut 2005;54:134-41. 
12. Deng X, Zhang X, Li W, et al. Chronic Liver Injury Induces Conversion of Biliary Epithelial Cells into Hepatocytes. Cell Stem Cell. 2018;23:114-22.e3.

13. Bird TG, Müller M, Boulter L, et al. TGF $\beta$ inhibition restores a regenerative response in acute liver injury by suppressing paracrine senescence. Sci Transl Med 2018;10:eaan1230.

14. Lee J, Park JS, Roh YS. Molecular insights into the role of mitochondria in non-alcoholic fatty liver disease. Arch Pharm Res 2019;42:935-46.

15. Dili A, Bertrand C, Lebrun V, et al. Hypoxia protects the liver from Small For Size Syndrome: A lesson learned from the associated liver partition and portal vein ligation for staged hepatectomy (ALPPS) procedure in rats. Am J Transplant 2019;19:2979-90.

16. Langiewicz M, Graf R, Humar B, et al. JNK1 induces hedgehog signaling from stellate cells to accelerate liver regeneration in mice. J Hepatol 2018;69:666-75.

17. Moro L. Mitochondrial Dysfunction in Aging and Cancer. J Clin Med 2019;8:1983.

18. Sorrentino V, Menzies KJ, Auwerx J. Repairing Mitochondrial Dysfunction in Disease. Annu Rev Pharmacol Toxicol. 2018;58:353-89.

19. Dela Cruz CS, Kang MJ. Mitochondrial Dysfunction and Damage Associated Molecular Patterns (DAMPs) in Chronic Inflammatory Diseases. Mitochondrion 2018;41:37-44.

20. Begriche K, Igoudjil A, Pessayre D, et al. Mitochondrial Dysfunction in NASH: Causes, Consequences and

Cite this article as: Li Z, Liang $\mathrm{Y}$, Ying $\mathrm{H}$, Chen $\mathrm{M}$, He $\mathrm{X}$, Wang Y, Tong Y, Cai X. Mitochondrial dysfunction attenuates rapid regeneration in livers with toxin-induced fibrosis. Ann Transl Med 2021;9(7):527. doi: 10.21037/atm-20-4639
Possible Means to Prevent It. Mitochondrion 2006;6:1-28.

21. Tomita K, Teratani T, Suzuki T, et al. Acyl-

CoA:cholesterol acyltransferase 1 mediates liver fibrosis by regulating free cholesterol accumulation in hepatic stellate cells. J Hepatol 2014;61:98-106.

22. Xiang DM, Sun W, Ning BF, et al. The HLF/IL-6/STAT3 feedforward circuit drives hepatic stellate cell activation to promote liver fibrosis. Gut 2018;67:1704-15.

23. Tarlow BD, Pelz C, Naugler WE, et al. Bipotential adult liver progenitors are derived from chronically injured mature hepatocytes. Cell Stem Cell 2014;15:605-18.

24. Font-Burgada J, Shalapour S, Ramaswamy S, et al. Hybrid Periportal Hepatocytes Regenerate the Injured Liver without Giving Rise to Cancer. Cell 2015;162:766-79.

25. García-Pérez R, Ferrer Fábrega J, Varona-Bosque A, et al. Role of Kupffer cells in the progression of CRC liver metastases after the first stage of ALPPS. Sci Rep 2018;8:8089.

26. Mederacke I, Hsu CC, Troeger JS, et al. Fate tracing reveals hepatic stellate cells as dominant contributors to liver fibrosis independent of its aetiology. Nat Commun 2013;4:2823.

27. Cook D, Achanta S, Hoek JB, et al. Cellular network modeling and single cell gene expression analysis reveals novel hepatic stellate cell phenotypes controlling liver regeneration dynamics. BMC Syst Biol 2018;12:86.

28. Kisseleva T, Cong M, Paik Y, et al. Myofibroblasts revert to an inactive phenotype during regression of liver fibrosis. Proc Natl Acad Sci U S A 2012;109:9448-53. 


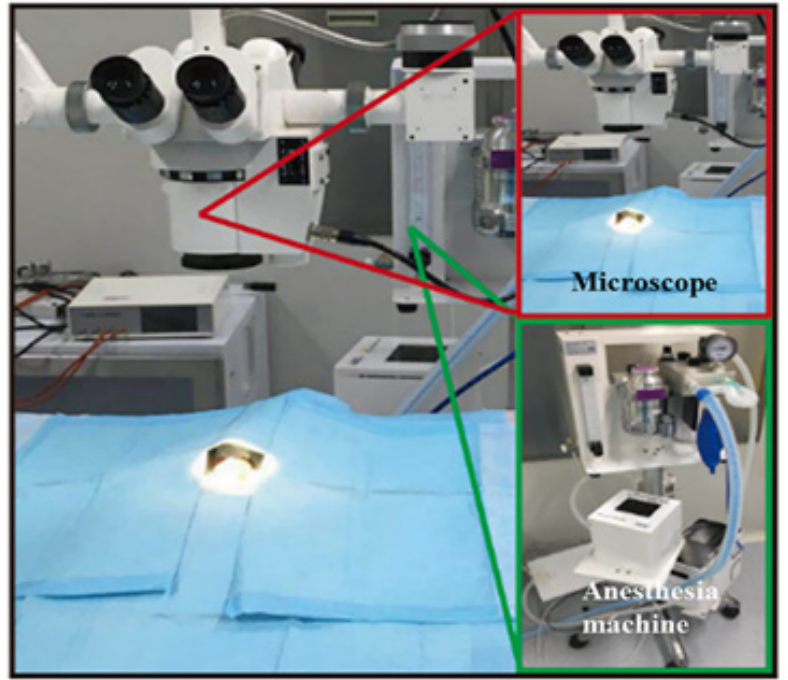

(A)

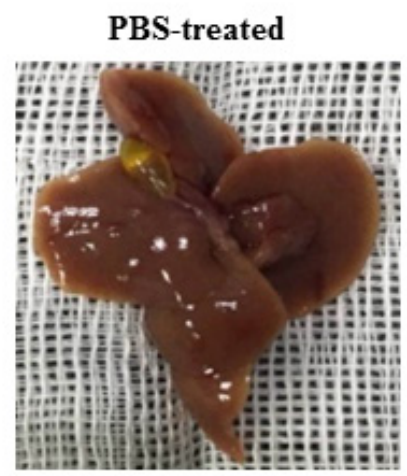

TAA-treated

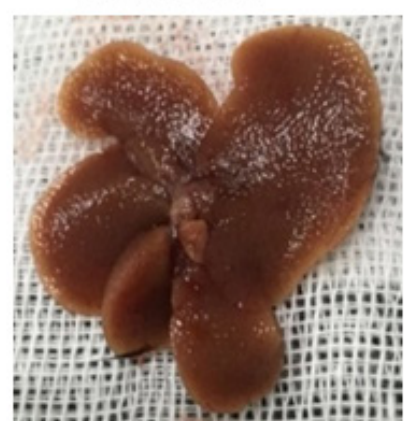

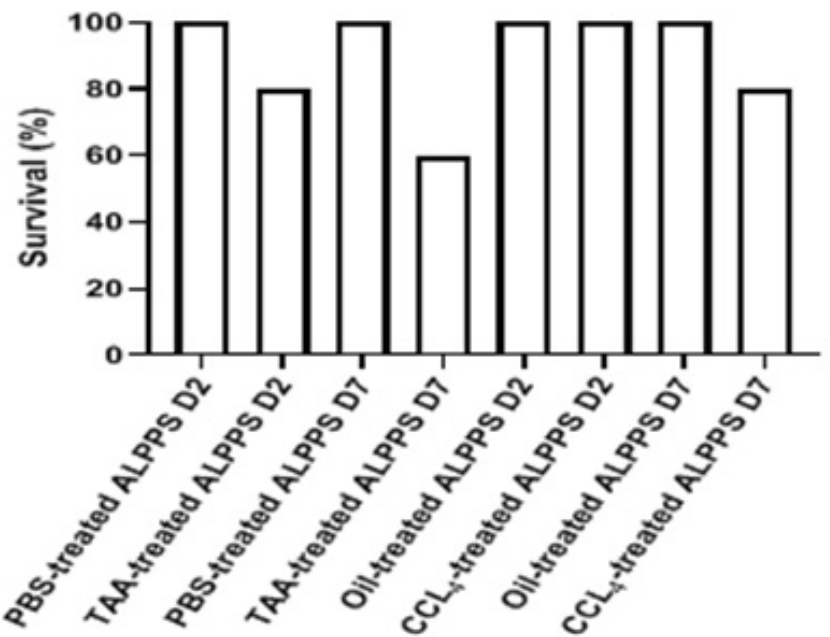

(B)
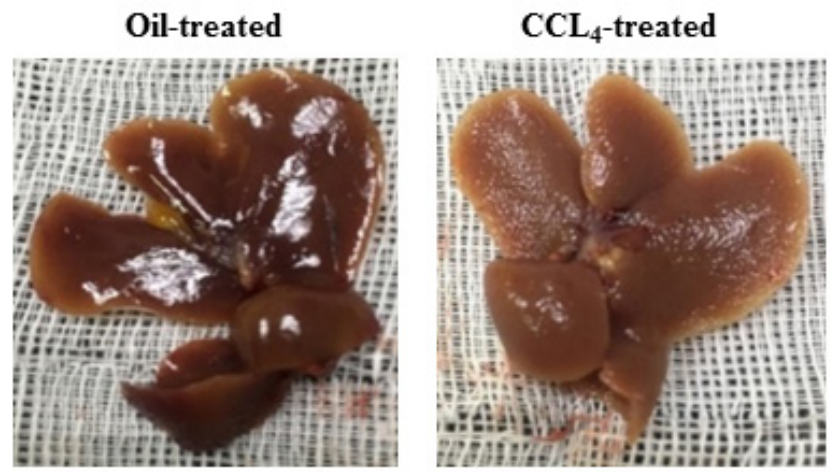

(C)

Figure S1 Establishment of fibrosis models. (A) Pictures of the apparatus; (B) Specimens of each group; (C) Mortality in each group during the associating liver partition and portal vein ligation for staged hepatectomy (ALPPS) procedure. 


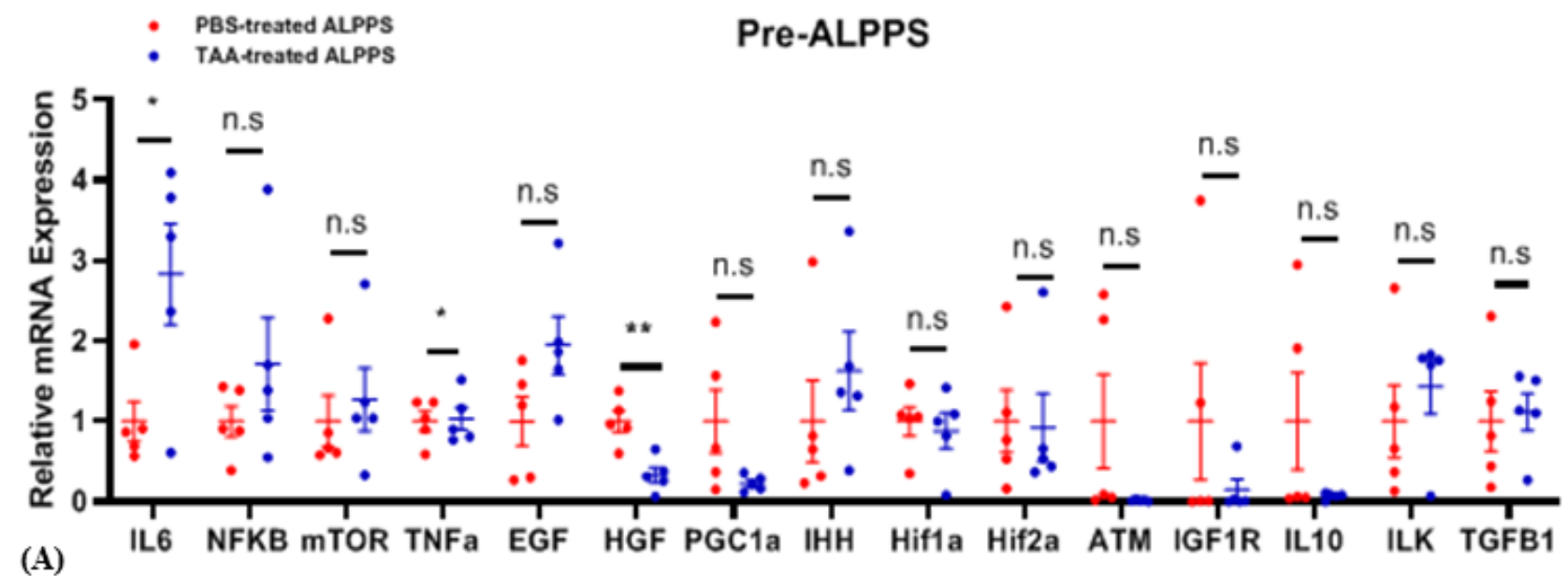

(A)

- PBS-treated ALPPS

- TAA-treated ALPPS

Post-ALPPS D2

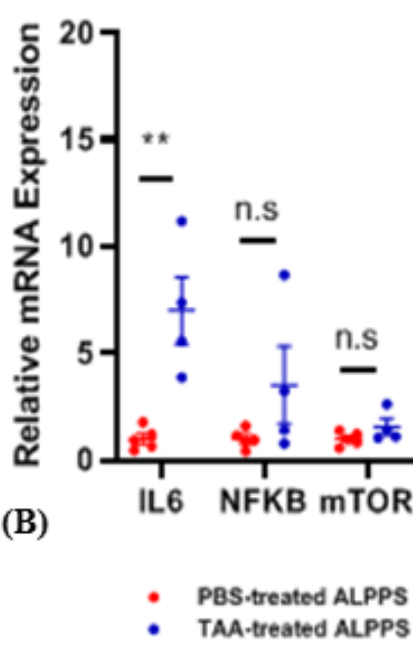

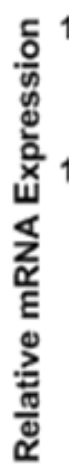

(C)

Post-ALPPS D7

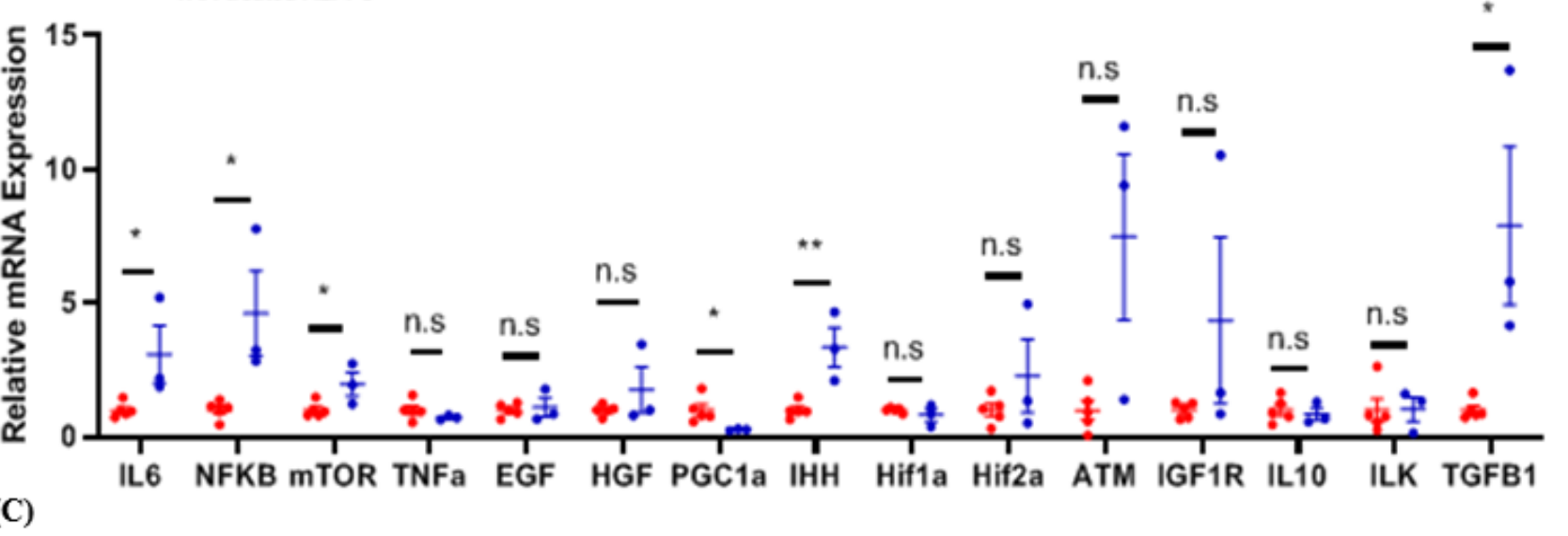

Figure S2 Several regenerative pathways during ALPPS in PBS- or TAA-treated models. (A) RNA expression pre-ALPPS; (B) RNA expression post-ALPPS day 2; (C) RNA expression post-ALPPS day $7 .{ }^{*} \mathrm{P}<0.05,{ }^{* *} \mathrm{P}<0.01$, and ${ }^{* * *} \mathrm{P}<0.001$. TAA, thioacetamide; PBS, phosphate buffered-saline; ALPPS, associating liver partition and portal vein ligation for staged hepatectomy; $\mathrm{n}=5$ mice for each condition. 
Table S1 Materials information (primers in this study)

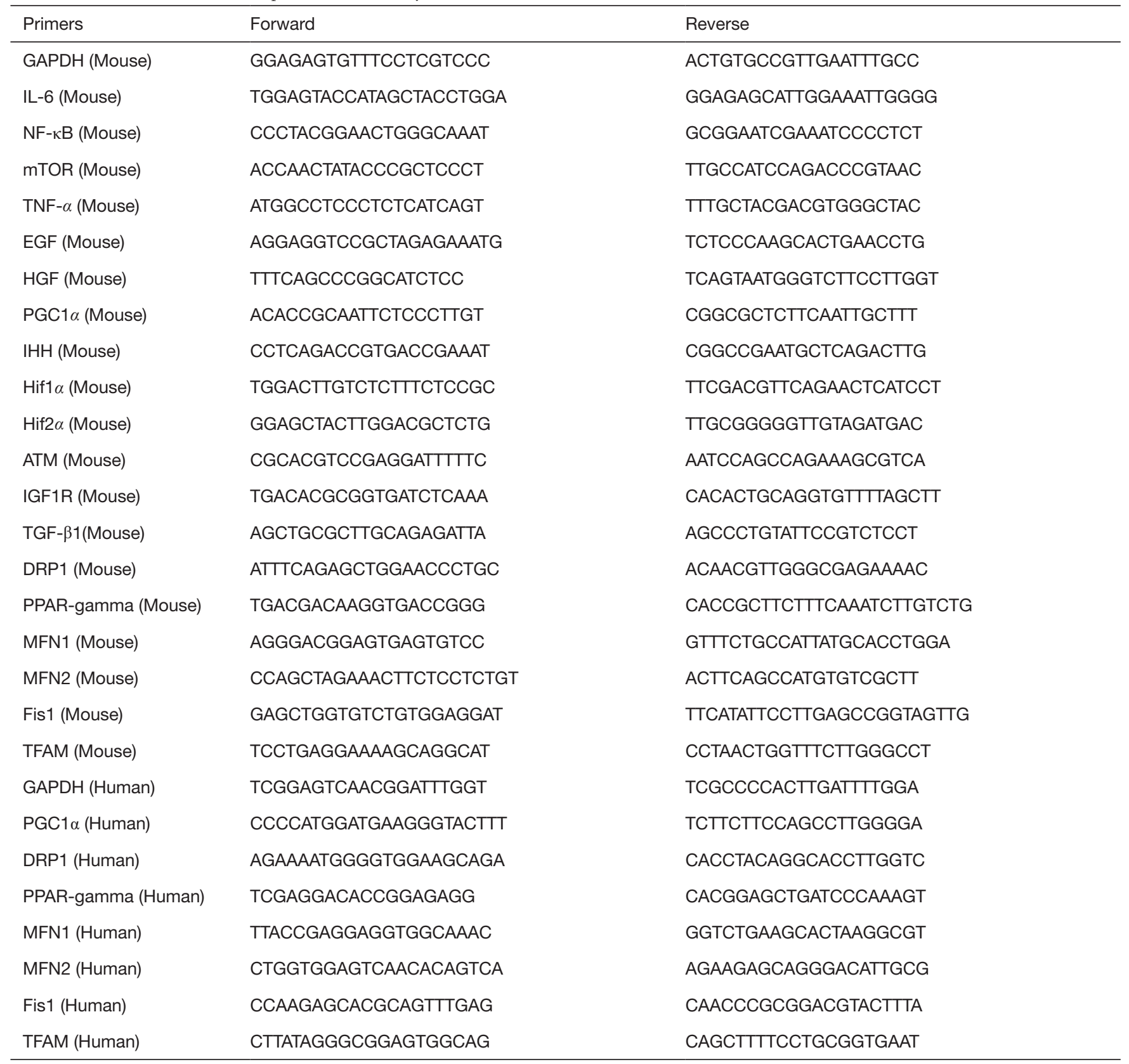

(c) Annals of Translational Medicine. All rights reserved. 
Table S2 Materials information (Primers, antibodies, agents and softwares in this study)

\begin{tabular}{|c|c|c|}
\hline & Source & Identifier \\
\hline Rabbit polyclonal anti-ACTB & Abcam & ab8227 \\
\hline Rabbit polyclonal anti-Ki-67 & Abcam & ab15580 \\
\hline Rabbit polyclonal anti- $\alpha-S M A$ & Abcam & ab5694 \\
\hline \multicolumn{3}{|l|}{ Reagents } \\
\hline Sirius Red & Solarbio & G1471 \\
\hline Haematoxylin \& Eosin Solution & Solarbio & G1120 \\
\hline Thioacetamide (TAA) & Sigma & 163678 \\
\hline Mitochondrial membrane potential assay kit with JC-1 & Beyotime & C2006 \\
\hline Lipid Peroxidation MDA Assay Kit & Beyotime & S0131S \\
\hline ATP Assay Kit & Beyotime & S0026 \\
\hline Apoptosis & YEASEN & 40305ES20 \\
\hline CCK8 & YEASEN & 40203ES60 \\
\hline \multicolumn{3}{|l|}{ Software and Algorithms } \\
\hline GraphPad Prism & GraphPad Software & Version 5.0.1 \\
\hline Adobe Photoshop CS5 & Adobe & Version 12.0.3 \\
\hline
\end{tabular}

